\title{
Enhancement Coupling Method of Microstrip Ring Resonator (MRR) Design for Different Material Sensor Characterization
}

\author{
Z. Zakaria, H. Nornikman, M. Abdulmalek, M. K. Ismail, S. Siam
}

\begin{abstract}
This work is to design a microstrip ring resonator (MRR) sensor that has the capability to measure the Q-factor and dielectric constant of the selective material. The first step is to design a basic microstrip ring resonator, called Design A. Then the enhancement coupling method of microstrip ring resonator, called Design $B$ is done to improve the performance of the return loss and to ensure the wanted resonant frequency. The performance of this enhancement coupling method of microstrip ring resonator shows of the resonant frequency at $2.096 \mathrm{GHz}$ with the return loss of $22.063 \mathrm{~dB}$ and bandwidth of $10 \mathrm{MHz}$ in between of $2.090 \mathrm{GHz}$ and $2.100 \mathrm{GHz}$. Using this return loss and the resonant frequency, the $Q$-factor can be calculated. Then, this microstrip ring resonator with the selective material under test (MUT) or namely as the sample are simulated and compared with the air $\left(\varepsilon_{r}=1\right)$ as the reference sample. The MUT that apply in this work are Roger 5880 $\left(\varepsilon_{r}=2.2\right)$, Roger $4350\left(\varepsilon_{r}=3.48\right)$ and FR-4 $\left(\varepsilon_{r}=4.4\right)$ while the measured dielectric constant that captured are $0.958,2.163,3.437$, 4.360 , respectively.
\end{abstract}

Keywords: Microwave ring resonator; Q-factor; resonant frequency, dielectric constant, permittivity

\section{INTRODUCTION}

$\mathrm{D}$ ielectric constant or sometimes called permittivity $\varepsilon_{r}$ is the important and decisive parameters that used to measure the material characteristic, especially in radio frequency and microwave range area [1]. The dielectric properties for all material are different to each other's. So, the researcher must be measured first the material properties to ensured it used the correct material and acceptable to their measurement.

This dielectric constant value can be obtained by variation of microwave sensors, depends on the technique, material under test (MUT), the frequency used and others [2].

Revised Manuscript Received on October 22, 2019.

* Correspondence Author

Z. Zakaria*, Center for Telecommunication Research and Innovation (CeTRI), Faculty of Electronics and Computer Engineering (FKEKK), Universiti Teknikal Malaysia Melaka (UTeM), Durian Tunggal, Melaka, Malaysia. Email: zahriladha@utem.edu.my

H. Nornikman, Faculty of Engineering and Information Sciences, University of Wollongong in Dubai (UOWD), United Arab Emirates (UAE). Email: nornikman84@yahoo.com

M. Abdulmalek, Faculty of Engineering and Information Sciences, University of Wollongong in Dubai (UOWD), United Arab Emirates (UAE). Email: mohamedfareqmalek@uowdubai.ac.ae

M. K. Ismail, Center for Telecommunication Research and Innovation (CeTRI), Faculty of Electronics and Computer Engineering (FKEKK), Universiti Teknikal Malaysia Melaka (UTeM), Durian Tunggal, Melaka, Malaysia. Email: khairy@utem.edu.my

S. Siam, Center for Telecommunication Research and Innovation (CeTRI), Faculty of Electronics and Computer Engineering (FKEKK), Universiti Teknikal Malaysia Melaka (UTeM), Durian Tunggal, Melaka, Malaysia.
The examples technique that used currently is free space technique [3], resonant cavity technique [4], planar resonator technique [5], near-field sensors [6], dielectric probe [7] and transmission-line technique [8].

All technique is having its own limitation or weakness with different of the size of structure, accuracy, easy or not to manufacture, and sometimes depends it's on the material which is solid, gas or liquid. Planar resonator sensor is one of the easy, not-expensive to fabricate with no special sample handling. This sensor can apply at two different material of solid and liquid while it also covers the high temperature measurement.

The examples of this sensor that apply in their works are microfluidic planar resonator by Chretiennot [9], compact planar resonator by Lee [10], split ring resonator (SSRR) based microwave sensor by Alahnomi [11], and microfluidic circular substrate integrated waveguide CSIW Resonator Sensor by Bahar [12]. Ring resonator structure for microwave sensor is also can be defined as the basic structure that been research by several authors such as coupled ring resonator by Zarifi [13] and microwave ring resonator by Jilani [14],

The resonant sensor is considered designed to obtain a sharp oscillation at the selective wanted frequency. The relation between material under test and the resonator with the electromagnetic field has a capability to shift the resonant frequency $(f r)$ and effect the bandwidth value of the resonator. The shifted of the resonant frequency basically can be correlated with the dielectric properties of the material under test and the electric field at the current point where this material is located.

A preferable microwave resonator must be having a low accuracy, good return loss performance and acceptable Q-factor value depends on the industries that perform a different method to capture their objective and output. The Q-factor of the MUT is the important parameter that can straightly depends on the quality factor of the reference sample (empty sample) with the variation of the size, shape, dielectric properties and the distance between of the MUT and the resonant sensor. This microwave resonator sensor (MRS) usually applies the $\mathrm{GHz}$ for frequency for measuring their material electromagnetics properties as their standards.

In this work, firstly a basic and the enhancement design of the microstrip ring resonator (MRR) are design in CST Microwave Studio simulation software.

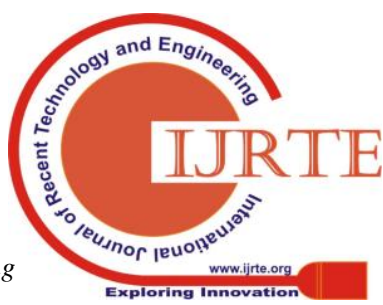




\section{Enhancement Coupling Method of Microstrip Ring Resonator (MRR) Design for Different Material Sensor Characterization}

Then, from the return loss and resonant frequency of these structures, the Q-factor and the dielectric constant of the material under test can be calculated using the curve fitting method. Lastly, the calculated and the known dielectric constant can be compared to shows the accurate value between these two values.

\section{MICROSTRIP RING RESONATOR DESIGN}

There are two stages of the microstrip ring resonator sensor design in this work. Firstly, is Design A with a basic microwave circular resonator. Then, it followed by the Design $B$ of the enchantment method of microstrip ring resonator sensor. All these two design stages are designed in CST Microwave Studio simulation software. FR-4 substrate with permittivity, $\varepsilon_{r}$ of 4.4 and thickness of $1.6 \mathrm{~mm}$ is used with the copper strip with the thickness of $0.035 \mathrm{~mm}$.

\section{A. Design A - Basic Microstrip Ring Resonator}

Microstrip ring resonator (MRR) structure is a closed-loop transmission line. Every application must be located at a desired resonant frequency to operate. To determine the wanted resonant frequency, the power is capacitive coupling through the feed-line and the gap between them. The important theory that must be taken place is the value of the different dielectric constant can be obtained when the substrate surface is located at the different place. So, this situation will effect the resonant frequency.

This microstrip ring resonator is planned and consider by the mathematical analysis using several formulas Before design the basic microstrip ring resonator, the resonant frequency of the must be chosen as the based calculation using the formula in Equation (1):

$$
f r=\frac{1}{2 \pi \sqrt{L C}}
$$

Inductance, $\mathrm{L}$ can be determined by Equation (2):

$$
L=\mu_{o} R_{m}\left(\operatorname{in} \frac{8 R_{m}}{h+w}-0.5\right)
$$

With $R m=$ main radius of the ring, $h=$ height of the substrate and $W=$ width of the feed-line. The capacitor, $C$ can change the resonant frequency value and it can be obtained by using Equation (3):

$$
C=\frac{\varepsilon_{r o} \varepsilon_{r} A}{d}
$$

Where $A=$ area of the gap, $d=$ Distance of the gap and $\varepsilon_{r}=$ relative permittivity of dielectric presents between the plates. The feed-line dimension and coupling can be considered using the subsequent equations which the Equation (4) is to calculate the area, $A$.

$$
\begin{gathered}
A=\frac{Z_{o}}{60} \sqrt{\frac{\varepsilon_{r}+1}{2}}+\frac{\varepsilon_{r}+1}{\varepsilon_{r}-1}\left(0.23+\frac{0.11}{\varepsilon_{r}}\right) \\
\frac{w}{d}=\frac{8 e^{A}}{e^{2 A}-2}
\end{gathered}
$$

Where $d$ is the thickness of the substrate. The feedline and coupling gap are obtained by using Equation (6) and Equation (7) respectively.

$$
\begin{gathered}
l=\frac{\lambda g}{4} \\
\varepsilon_{r}=-292.71 f_{r}(x)^{2}+1163.5 f(x)-1151.8
\end{gathered}
$$

$\therefore \lambda \mathrm{g}$ is the wavelength at the given frequency.

Where effective permittivity, $\varepsilon_{e f f}$

$$
\varepsilon_{e f f}=\frac{\varepsilon_{r}+1}{2}+\frac{\varepsilon_{r}-1}{2}\left(\frac{1}{\sqrt{1+\frac{12 d}{w}}}\right)
$$

Figure 1 shows the basic microstrip ring resonator. This structure is design with the feedline and circular ring. The port is connected with the feedline part. A coupling gap is basically design did not connect between feedline and ring resonator structure.

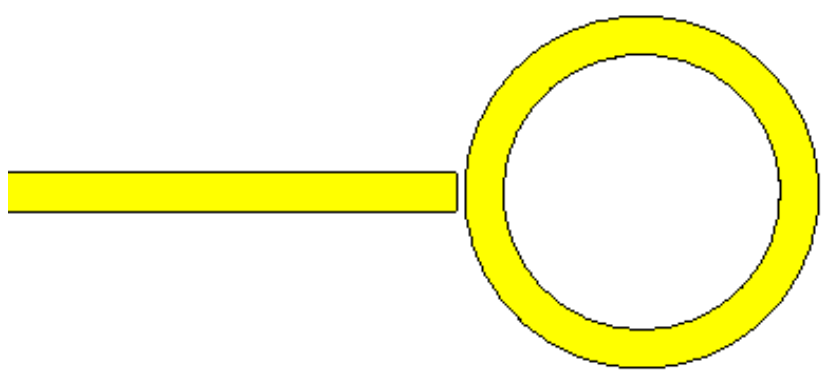

Figure 1: Basic microstrip ring resonator, Design $A$

Figure 2 represents the resonant frequency, $S_{1 l}$ performance for the basic microstrip ring resonator sensor. The compulsory parameters that consider in this work are the resonant frequency and the bandwidth (BW) performance. In this case, it shows the resonant frequency at $2.089 \mathrm{GHz}$ with the return loss of - $1.497 \mathrm{~dB}$. This structure does not fulfill the requirement better $-10 \mathrm{~dB}$. Then, the enhancement of the resonator structure can be done in the next stage.

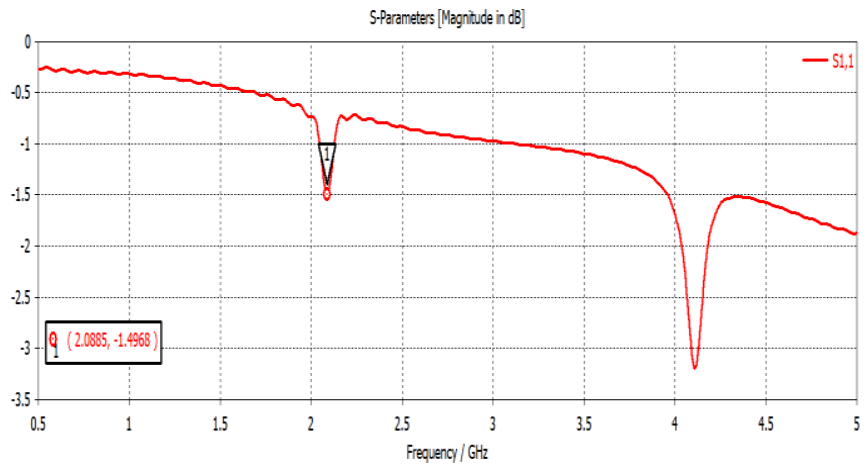

Figure 2: The $S_{11}$ of the basic microstrip ring resonator sensor 


\section{B. Design B - Enhancement Microstrip Ring Resonator}

To cater the problem in the Design $A$, an enhancement coupling method to improve the strength of the coupling in the sensor are introduce by Design $B$. The additional of Y-shaped is the part of the enhanced coupling periphery functional to decrease the insertion loss and improve the capacitance gap in the sensor, respectively. This enhances coupling method is usually applied in radio frequency filter design. The dimension of the enhancement coupling method of microstrip ring resonator, Design $B$ is illustrating in Figure 3. Table I shows the dimension of the enhancement coupling method of microstrip ring resonator of Design $B$.

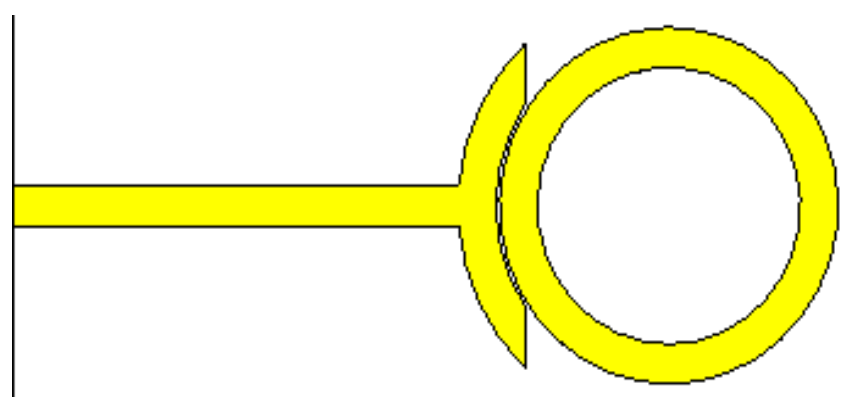

Figure 3: Design of enhancement coupling method of microstrip ring resonator, Design $B$

Table I: Dimension of enhancement coupling method of microstrip ring resonator, Design $B$

\begin{tabular}{|c|c|c|}
\hline Parameter & Symbol & Dimension (mm) \\
\hline Substrate thickness & $T_{s}$ & 1.60 \\
\hline Length of substrate & $L_{g}$ & 80.66 \\
\hline Width of substrate & $W_{g}$ & 55.96 \\
\hline Length of feedline & $L_{f}$ & 18.86 \\
\hline Width of feedline & $W_{f}$ & 2.50 \\
\hline Outer ring & $R_{o}$ & 13.25 \\
\hline Inner ring & $R_{i}$ & 10.75 \\
\hline Gap & $G$ & 0.30 \\
\hline
\end{tabular}

Figure 4 represents the resonant frequency of the enhancement coupling method of microstrip ring resonator, Design $B$. It shows that this structure operates at $2.096 \mathrm{GHz}$ with the return loss of $-22.063 \mathrm{~dB}$. It also shows the bandwidth $10 \mathrm{MHz}$ in between of $2.090 \mathrm{GHz}$ and $2.100 \mathrm{GHz}$. This parameter can be used and apply in the next Q-factor calculation and measured the dielectric properties.

Besides that, the electromagnetic field in the microstrip ring resonator can be seen using this software, shown in Figure 5. Usually, the microwave planar resonator sensor design has a ground conductor. From the ground conductor, the electric field is propagated in quasi-TEM mode between the substrate and material above the substrate, basically, it is copper. After that, the characteristic impedance of the planar transmission line necessity be instantly coordinated with the frequency.

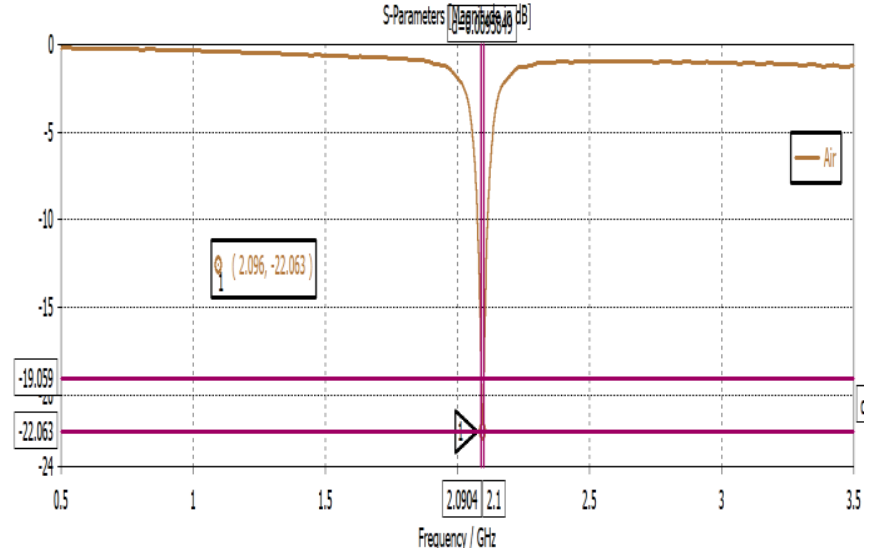

Figure 4: Performance of enhancement coupling method of microstrip ring resonator, Design $B$

The maximum volume of the electric field is important to ensure the high sensitivity of the resonator sensor. Figure 5 illustrates the electric field distribution for microstrip ring resonator, Design $B$. Higher electric field part is referring by the red color, follows by yellow, green, light blue and lowest part with dark blue. In this case, the ring and the feedline is the best part that has an acceptable accuracy for this resonator. So, the material under test (sample) can be located at this part to give the acceptable value of the Q-factor and dielectric constant.

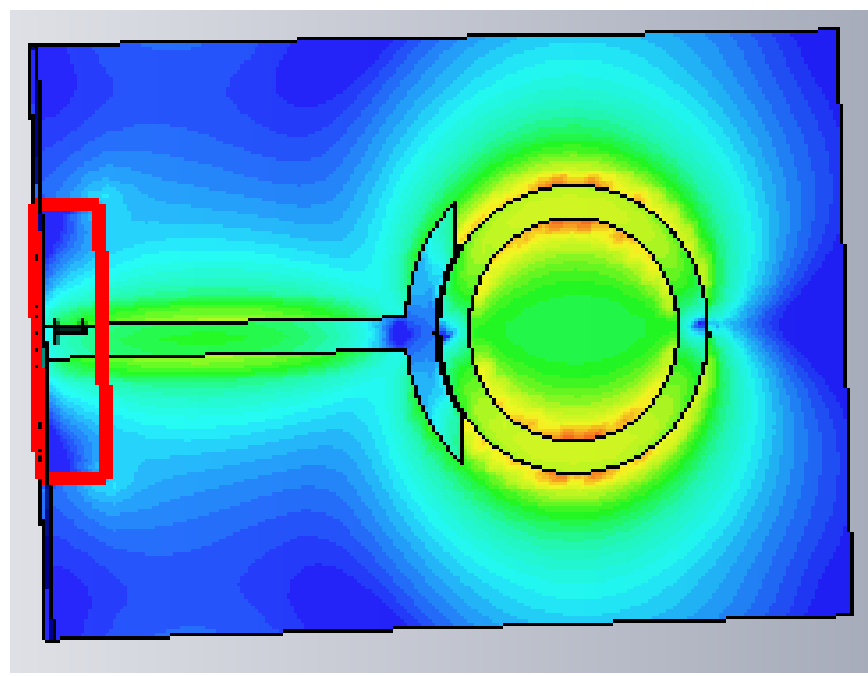

Figure 5: Electric filed distribution for microstrip ring resonator, Design $B$

\section{Q-FACTOR AND DIELECTRIC PROPERTIES OF MATERIAL}

This section focuses on the Q-factor and dielectric properties of material measurement. Firstly, it starts with the added a MUT (sample) at the above the microstrip ring resonator. This sample is locating on the feed-line and the ring such as illustrated in Figure 6. The sample must be located at the maximum electric field point to effect the decreasing of Q-factor value while also effect to reduce the resonant frequency performance. 


\section{Enhancement Coupling Method of Microstrip Ring Resonator (MRR) Design for Different Material Sensor Characterization}

In this case four different samples that consider are FR-4 $\left(\varepsilon_{r}\right.$ $=4.4)$, Roger $5880\left(\varepsilon_{r}=2.2\right)$, Roger 4350B $\left(\varepsilon_{r}=3.48\right)$ and air. The air is considered as the reference sample, because its dielectric constant is 1.0. The size of each sample is width, $w=$ $17.0 \mathrm{~mm}$ while the length, $l=25.0 \mathrm{~mm}$.

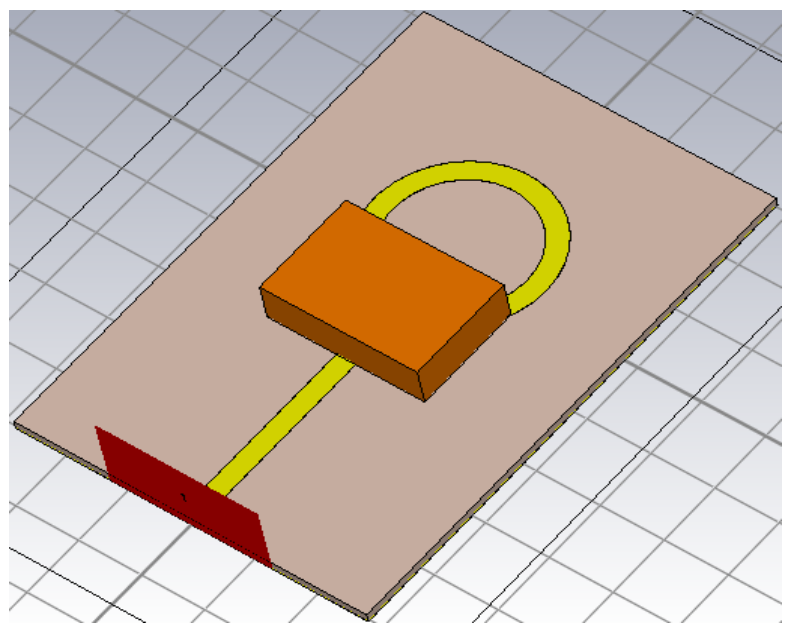

Figure 6: The location of sample on the microstrip ring resonator sensor

Figure 7 shows the effect on the resonant frequency with different samples on microstrip ring resonator sensor. It shows that the microstrip ring resonator with air and microstrip ring resonator without the sample has the same resonant frequency of $2.096 \mathrm{GHz}$. It is because microstrip ring resonator without sample basically has the same dielectric properties.

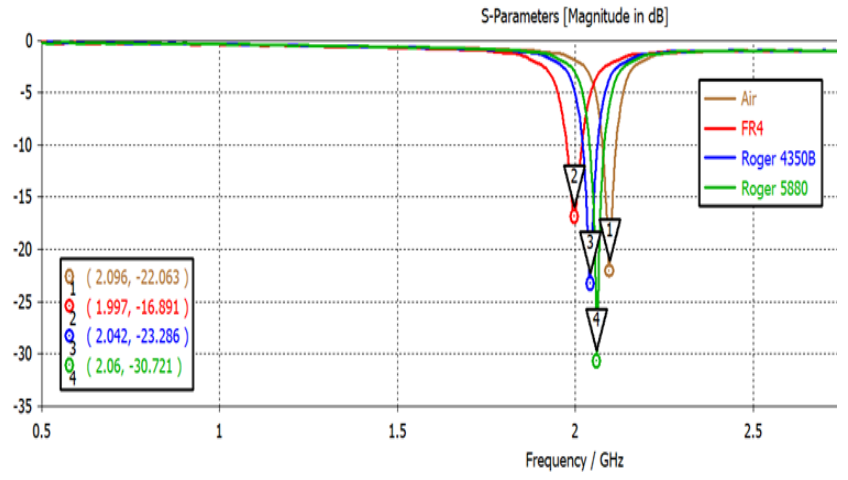

Figure 7: Effect on the resonant frequency with different samples on microstrip ring resonator sensor

This is different with the other three samples which are shifted to left compared with the reference sample of air. It shows that the resonant frequency for Roger 5880, Roger 4350B and FR-4 are $2.06 \mathrm{GHz}, 2.042 \mathrm{GHz}$ and $1.997 \mathrm{GHz}$ with return loss of $-30.721 \mathrm{~dB},-23.286 \mathrm{~dB}$ and $-16.891 \mathrm{~dB}$, respectively. This situation happens since the maximum electric field of the resonator is perturbed at the sample and besides that, the fringing fields are intensive move into the sample at the above.

Using this information, the Q-factor of the microstrip ring resonator can be defined by applying the Equation (9).

$$
Q=\frac{2 f_{c}}{B W}
$$

$$
Q=\frac{2(2.096 \mathrm{GHz})}{0.0095849 \mathrm{GHz}}=437
$$

By applying this formula, the Q-factor of the microstrip ring resonator sensor with the reference sample is shown as 437 . The Q-factor for Roger 5880, Roger 4350B, and FR-4 are 190, 1127 and 449 using the $-3 \mathrm{~dB}$ bandwidth $0.0036547 \mathrm{GHz}$, $0.0090973 \mathrm{GHz}$, and $0.021045 \mathrm{GHz}$, respectively. The highest Q-factor is achieved by Roger 5880, followed by Roger 4350B.

It shows that the addition sample can change the Q-factor of the microstrip ring resonator. Inappropriately, the reduction or increasing value are not static depends on the dielectric constant. This is existing since each of the samples is located with variation permittivity, but it also did not have the same thickness. Table II shows the several performances of the resonant frequency with different samples on microstrip ring resonator sensor (simulation)

Besides that, the resonant frequency shift, $f_{\text {shift }}$ percentage of the simulation results can be calculated for each sample by using Equation (10) below:

$$
f_{\text {shift }}=\frac{f_{o}-f_{\text {sample }}}{f_{o}} \times 100
$$

Table II: The performance of the resonant frequency with different samples on microstrip ring resonator sensor (simulation)

\begin{tabular}{|c|c|c|c|c|c|}
\hline $\begin{array}{c}\text { Type } \\
\text { of } \\
\text { sample }\end{array}$ & $\begin{array}{c}\text { Permittivit } \\
\mathbf{y}\left(\boldsymbol{\varepsilon}_{\boldsymbol{r}}\right)\end{array}$ & $\begin{array}{c}\text { Freque } \\
\mathbf{n c y} \\
\mathbf{( G H z )}\end{array}$ & $\begin{array}{c}\text { Different of } \\
\text { frequency } \\
\mathbf{( G H z )} \text { with } \\
\text { reference }\end{array}$ & $\begin{array}{c}\text { Percenta } \\
\text { ge of } \\
\text { shifting } \\
\mathbf{( \% )}\end{array}$ & $\begin{array}{c}\text { Q- } \\
\text { factor }\end{array}$ \\
\hline $\begin{array}{c}\text { Air } \\
\text { (referen } \\
\text { ce) }\end{array}$ & 1.0 & 2.096 & 0 & 0 & 437 \\
\hline $\begin{array}{c}\text { Roger } \\
5880\end{array}$ & 2.2 & 2.060 & 0.036 & 1.7 & 1127 \\
\hline $\begin{array}{c}\text { Roger } \\
4350\end{array}$ & 3.48 & 2.042 & 0.054 & 2.6 & 449 \\
\hline FR-4 & 4.4 & 1.997 & 0.099 & 4.7 & 190 \\
\hline
\end{tabular}

Figure 8 represents the fabricated microstrip ring resonator sensor, design by FR-4 structure. This design is the same as the simulation in CST. The SMA connector is connected with the feedline and followed the ring-shaped structure.

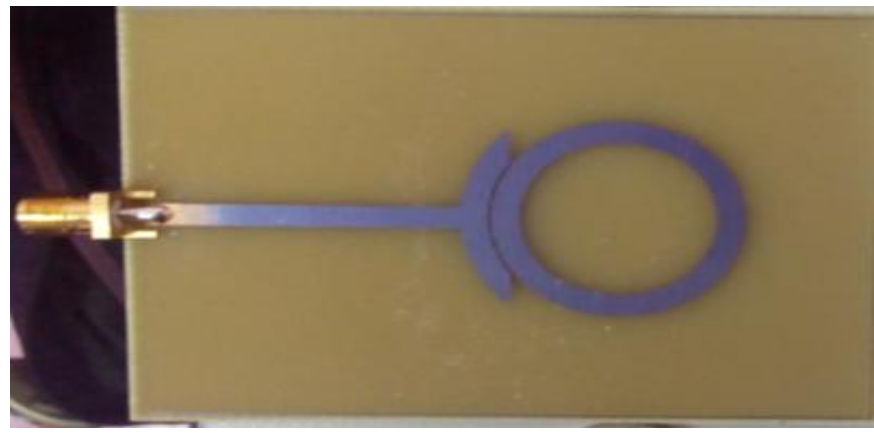

Figure 8: The fabricated microstrip ring resonator sensor 
Figure 9(a) represents the measurement setup of microstrip ring resonator sensor using vector network analyzer (VNA). It shows that the SMA connector is connected with the cable wire to VNA. Figure 9(b) shows the placement of the sample on the fabricated microstrip ring resonator.

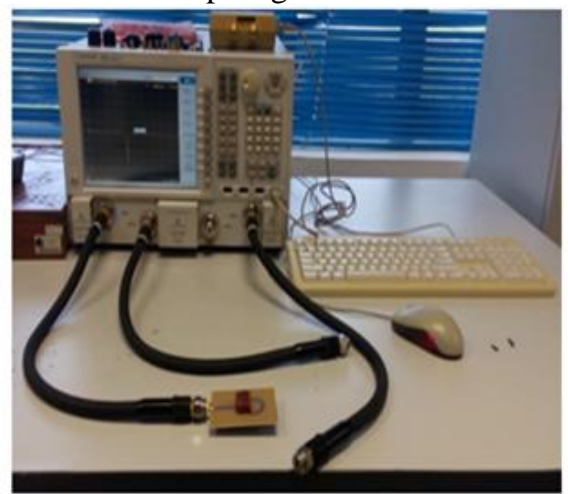

(a)

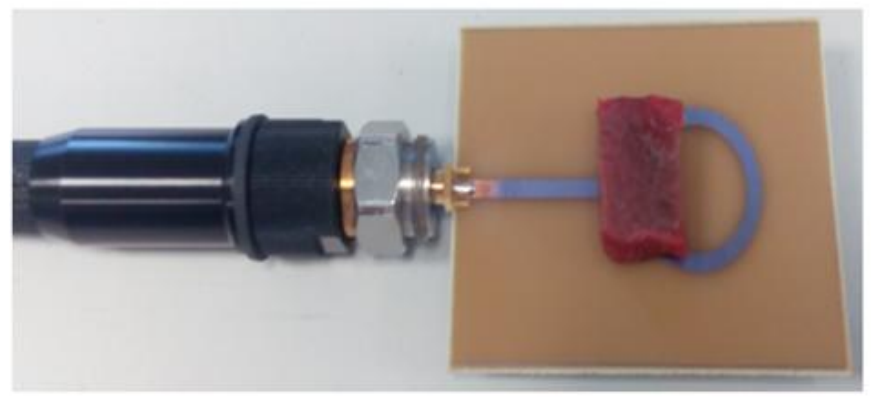

(b)

Figure 9: Measurement setup, (a) the one microstrip ring resonator sensor connected with vector network analyzer (VNA), (b) sample on the microstrip ring resonator sensor.

After measuring process done, it slightly shows same resonant frequency results with the simulation in CST Microwave Studio that achieve $2.096 \mathrm{GHz}$ with return loss reduction to $-11.8 \mathrm{~dB}$ and the bandwidth of $0.019888 \mathrm{GHz}$. Using the same Q-factor formula, the value that calculated is 211 only, compared with the simulation that shows 437 . Figure 10 and Table III shows the performance of the enhancement coupling method of microstrip ring resonator, Design $\mathrm{B}$ (fabricated).

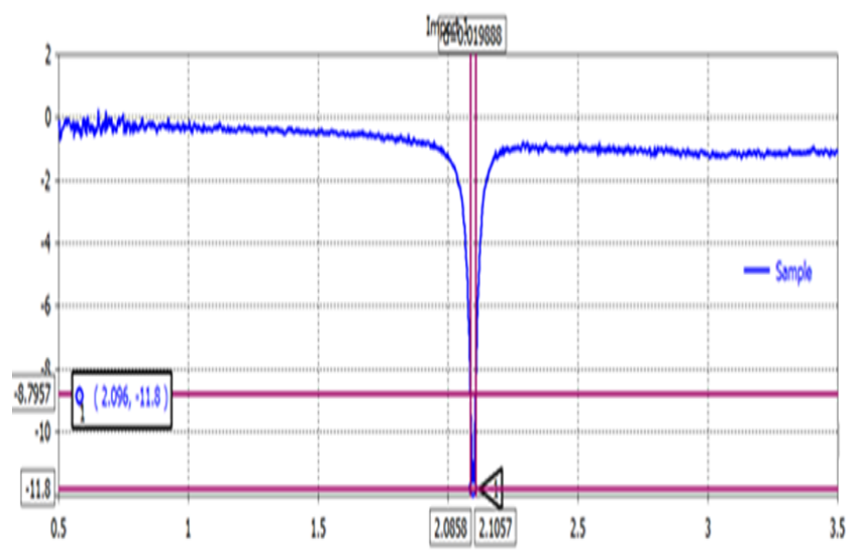

Figure 10: Performance of enhancement coupling method of microstrip ring resonator, Design $B$ (fabricated)
Table III: The performance of the resonant frequency with different samples on microstrip ring resonator sensor

$$
\text { (fabricated) }
$$

\begin{tabular}{|c|c|c|c|c|c|}
\hline $\begin{array}{c}\text { Type of } \\
\text { sample }\end{array}$ & $\begin{array}{c}\text { Permittivi } \\
\mathbf{t y}\left(\boldsymbol{\varepsilon}_{\boldsymbol{r}}\right)\end{array}$ & $\begin{array}{c}\text { Frequenc } \\
\mathbf{y}(\mathbf{G H z})\end{array}$ & $\begin{array}{c}\text { Different of } \\
\text { frequency } \\
(\mathbf{G H z}) \text { with } \\
\text { reference }\end{array}$ & $\begin{array}{c}\text { Percent } \\
\text { age of } \\
\text { shifting } \\
(\%)\end{array}$ & $\begin{array}{c}\mathbf{Q} \\
\text {-factor }\end{array}$ \\
\hline $\begin{array}{c}\text { Air } \\
\text { (referen } \\
\text { ce) }\end{array}$ & 1.0 & 2.096 & 0 & 0 & 211 \\
\hline $\begin{array}{c}\text { Roger } \\
5880\end{array}$ & 2.2 & 2.075 & 0.021 & 1.7 & 178 \\
\hline $\begin{array}{c}\text { Roger } \\
4350\end{array}$ & 3.48 & 2.045 & 0.051 & 2.6 & 535 \\
\hline FR-4 & 4.4 & 2.0 & 0.096 & 4.7 & 552 \\
\hline
\end{tabular}

By using the curve fitting method, the Equation (11) for the MUTs dielectric constant is extracted from the measured data of the selective samples. Figure 11 shows the relationship between the resonance frequency and the dielectric constant or permittivity graphically.

$$
\varepsilon_{r}=-292.71 f_{r}(x)^{2}+1163.5 f(x)-1151.8
$$

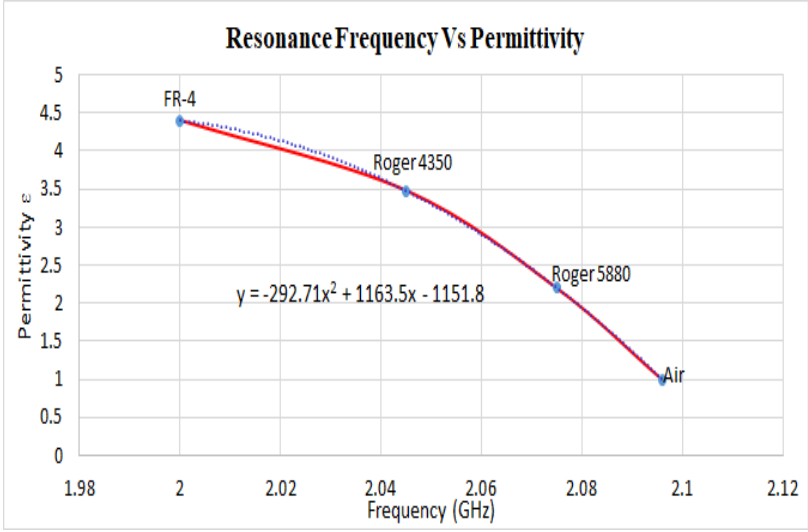

Figure 11: Curve fitting method for dielectric constant value

It shows that Table IV describes the calculated dielectric constant from the equation. Compare with the theoretical dielectric constant and the calculated dielectric constant using the equation, it shows that the air shows the highest error with $4.23 \%$ while the FR-4 shows the lowest error with only 0.91 $\%$. It shows that the calculated dielectric constant of the air, Roger 5880, Roger 4350 and FR-4 is 0.958, 2.163, 3.437 and 4.360 compared with the theoretical dielectric constant of 1 , $2.2,3.48$ and 4.4 , respectively.

Table IV: The calculated dielectric constant from the equation

\begin{tabular}{|c|c|c|c|c|}
\hline $\begin{array}{c}\text { Type of } \\
\text { sample }\end{array}$ & $\begin{array}{c}\text { Frequency } \\
(\mathrm{GHz})\end{array}$ & $\begin{array}{c}\text { Theoritical } \\
\text { dielectric } \\
\text { constant }\left(\varepsilon_{r}\right)\end{array}$ & $\begin{array}{c}\text { Calculated dielectric } \\
\text { constant }\left(\varepsilon_{r}\right) \text { from } \\
\text { equation }\end{array}$ & $\begin{array}{c}\text { Error } \\
(\%)\end{array}$ \\
\hline Air & 2.096 & 1 & 0.958 & 4.23 \\
\hline $\begin{array}{c}\text { Roger } \\
5880\end{array}$ & 2.075 & 2.2 & 2.163 & 1.68 \\
\hline $\begin{array}{c}\text { Roger } \\
4350\end{array}$ & 2.045 & 3.48 & 3.437 & 1.24 \\
\hline FR-4 & 2.0 & 4.4 & 4.360 & 0.91 \\
\hline
\end{tabular}




\section{Enhancement Coupling Method of Microstrip Ring Resonator (MRR) Design for Different Material Sensor}

Characterization

\section{CONCLUSION}

This work successfully to design a microstrip ring resonator (MRR) sensor that has the capability to measure the Q-factor and dielectric constant of the selective material of Roger 5880, Roger 4350 and FR-4. The dielectric constant values between the theoretical dielectric constant and the calculated dielectric constant using the equation is acceptable with only little number of errors.

\section{ACKNOWLEDGMENT}

The authors would like to express our appreciation to Universiti Teknikal Malaysia Melaka (UTeM) in Melaka and Ministry of Higher Education (MOHE) of Malaysia for funding this work under the Geran Sanjungan Insentif Penerbitan Jurnal, UTeM, JURNAL/2018/FKEKK/Q00001. Also, thanks to Centre of Telecommunication Research and Innovation (CeTRI), Faculty of Electronic and Computer Engineering (FKEKK) and Centre for Research and Innovation Management (CRIM), UTeM. Lastly, thanks to Faculty of Engineering and Information Sciences, University of Wollongong in Dubai (UOWD), United Arab Emirates (UAE).

\section{REFERENCES}

1. M. S. Boybay, O. M. Ramahi, "Material characterization using complementary split-ring resonators", IEEE Transactions on Instrumentation and Measurement, 2012, vol. 61, no. 11, pp. 3039-3046,

2. J. Mata-Contreras, L. Su and F. Martín, "Microwave sensors based on symmetry properties and metamaterial concepts: A review of some recent developments (Invited paper)," 2017 IEEE 18th Wireless and Microwave Technology Conference (WAMICON), 2017, pp. 1-6

3. L. Zahid, M. F. B. A. Malek, H. Nornikman, N. A. Mohd Affendi, A. Ali, N. Hussin, B. H. Ahmad, and M. Z. A. Abdul Aziz, "Development of Pyramidal Microwave Absorber Using Sugar Cane Bagasse (SCB)," Progress in Electromagnetics Research, 2013, vol. 137, 687-702

4. X. Yi, Q.-F. Yang, K. Y. Yang, M.-G. Suh, K. Vahala, "Soliton frequency comb at microwave rates in a high-Q silica microresonator," Optica, 2015 , vol. 2, no. 12 , pp. $1078-1085$

5. A. A. M. Bahar, Z. Zakaria, S. R. A. Rashid, A. A. M. Isa, E. Ruslan and R. A. Alahnomi, "Microstrip planar resonator sensors for accurate dielectric measurement of microfluidic solutions," 2016 3rd International Conference on Electronic Design (ICED), 2016, pp. 416-421,

6. P. Hillger, J. Grzyb, U. Pfeiffer, A fully-integrated terahertz near-field sensor for super-resolution imaging in SiGe BiCMOS, $201641 \mathrm{~s}$ International Conference on Infrared, Millimeter, and Terahertz Waves, 2016, pp. 1-2

7. Y. S. Lee, F. H. Wee, K. Y. You, C. Y. Lee, Y. Y. Lee, L. Zahid, "Single layer microwave absorber based on rice husk-mwents composites," MATEC Web of Conferences, 2018, vol. 150, pp. 1-4

8. J. Roelvink, S. Trabelsi and S. O. Nelson, "A Planar Transmission-Line Sensor for Measuring the Microwave Permittivity of Liquid and Semisolid Biological Materials," IEEE Transactions on Instrumentation and Measurement, 2013, vol. 62, no. 11, pp. 2974-2982

9. T. Chretiennot, D. Dubuc, K. Grenier, "A microwave and microfluidic planar resonator for efficient and accurate complex permittivity characterization of aqueous solutions," IEEE Transactions on Microwave Theory and Techniques, 2013, vol. 61, no. 2, pp. 972-978

10. H.-J. Lee, J.-G. Yook, Droplet sensing using small and compact high-Q planar resonator based on impedance matching technique, Review of Scientific Instruments, 2016, vol. 87, no. 9, pp. 1-4

11. R. A. Alahnomi, Z. Zakaria, E. Ab. Ruslan, S. R. Rashid, A. A. Mohd Bahar, A. Shaaban, "Microwave bio-sensor based on symmetrical split ring resonator with spurline filters for therapeutic goods detection," PLoS One, 2017, vol. 12, no. 9, pp. 1-22,

12. A. A. Mohd Bahar, Z. Zakaria, A. A. Md Isa, Y. Dasril, R. A. Alahnomi, "The CSIW Resonator Sensor for Microfluidic Characterization Using

Defected Ground Structure," Journal of Telecommunication, Electronic and Computer Engineering (JTEC), 2018, vol. 10, no. 2-6, pp. 35-40

13. M. H. Zarifi, M. Daneshmand, "Wide dynamic range microwave planar coupled ring resonator for sensing applications," Applied Physics Letters, 2016, vol. 108, no. 23, pp. 1-4

14. M. T. Jilani, W. P. Wen, L. Y. Cheong, M. Z. ur Rehman, "A Microwave Ring-Resonator Sensor for Non-Invasive Assessment of Meat Aging", Sensors (Basel), 2016, vol. 16, no. 1, pp. 1-13

\section{AUTHORS PROFILE}

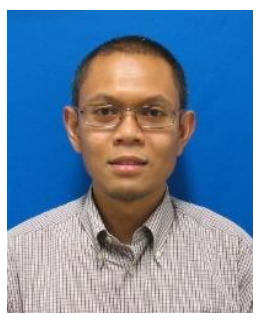

Zahriladha Zakaria received the $\mathrm{BE}$ and $\mathrm{ME}$ in Electrical and Electronic Engineering from the Universiti Teknologi Malaysia in 1998 and 2004, respectively. He obtained his Doctorate from The University of Leeds in 2010 in the field of Microwave Engineering. From 1998 to 2002, he was with STMicroelectronics, based in Malaysia where he worked as Product Engineer. He is currently a Professor and also the Manager of Centre for Telecommunication Research and Innovation (CeTRI) at the Faculty of Electronic and Computer Engineering, University Teknikal Malaysia Melaka, where he teaches Electronics, Microwave Engineering and Signal Processing. His research interests include a variety of microwave device developments such as planar and nonplanar microwave filters, amplifiers, and antennas. He also investigates radio wave propagation as well as energy harvesting for wireless sensor networks and signal processing.

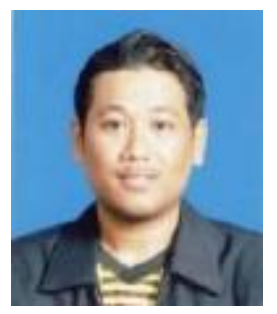

Nornikman Hassan graduated his $\mathrm{PhD}$ degree in Electronics Engineering from the Universiti Teknikal Malaysia Melaka (UTeM), Melaka, Malaysia in 2016. Before that, he received his Master Sciences (MSc) in Communication Engineering and Bachelor Engineering, B. Eng (Hons) in Communication Engineering, both in 2010 and 2007, respectively from Universiti Malaysia Perlis, Perlis, Malaysia. He is currently a Research Assistant at Faculty of Engineering and Information Sciences, University of Wollongong in Dubai (UOWD), United Arab Emirates (UAE). His research interests concern is antenna design, microwave absorber, and metamaterial of split ring resonator.

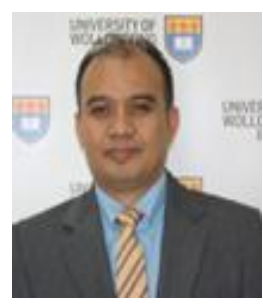

Mohd Fareq Abd Malek received his PhD in radio frequency and microwave transmission at University of Liverpool, United Kingdom (2008). He also graduates at the same university for his MSc (Eng) Microlectronics System and Telecommunications in 2004. Before that, he receives his B. Eng (Hons), Electronic and Communication Engineering in 1997. He is currently as an Associate Professor at Faculty of Engineering and Information Sciences, University of Wollongong in Dubai (UOWD). His research activities is in the area of telecommunication, electrical engineering, applied electromagnetic, microwave engineering, antenna and wireless communication

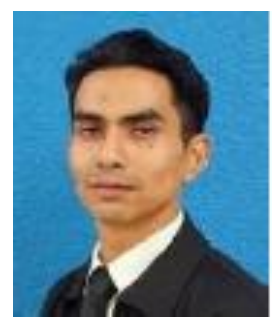

Mohd Khairy Ismail received the Master Sciences (MSc) in Electronics Engineering from the Universiti Teknikal Malaysia Melaka (UTeM), Melaka, Malaysia in 2016. Before that, he receives his bachelor's degree Electronics Engineering in Telecommunication from the Universiti Teknikal Malaysia Melaka (UTeM), Melaka in 2013. He is currently a Research Officer in UTeM Research and Innovation Management (CRIM), Universiti Teknikal Malaysia Melaka (UTeM). He also is a researcher in Centre for Telecommunication Research and Innovation (CeTRI), Faculty of Electronics and Computer Engineering (FKEKK), Universiti Teknikal Malaysia Melaka (UTeM). His research interests concern is wireless telecommunication, Long-Term Evolution (LTE). 